\title{
THE EXAMINATION OF THE ASSOCIATIONS AMONG PERFECTIONISM, SELF-HANDICAPPING, SELF-COMPASSION AND PSYCHOLOGICAL SYMPTOMS
}

\author{
Gizem Alaloğlu, \& Başak Bahtiyar \\ Department of Psychology, Maltepe University (Turkey)
}

\begin{abstract}
The aim of the current study was to examine the associations among perfectionism, self-handicapping, self-compassion and psychological symptoms. For this purpose, 653 volunteer participants (360 females and 293 males) whose ages were between 18 and $50(M=24.90, S D=7.57)$ were recruited from various cities in Turkey. Demographic Information Form, Multidimensional Perfectionism Scale (MPS), Self-Handicapping Scale (SHS), Self-Compassion Scale (SCS) and Brief Symptom Inventory (BSI) were administered in data collection. The result of the hierarchical regression analysis revealed that psychological symptoms were positively associated with socially prescribed perfectionism and self-handicapping, but negatively associated with self-compassion. Limitations, future directions and implications of the study were also provided.
\end{abstract}

Keywords: Perfectionism, self-handicapping, self-compassion, psychological symptoms.

\section{Introduction}

In literature perfectionism is considered as a risk and maintaining factor for various psychological problems (Egan, Wade, \& Shafran, 2011). However, some researchers claimed that perfectionism is a multidimensional construct and may not be a completely negative concept (Stoeber \& Otto, 2006). Moreover, different mechanisms are involved in the relationship between perfectionism and psychological health. Since perfectionism may cause some negative psychological consequences particularly in a failure situation (Stoeber, Schneider, Hussain, \& Matthews, 2014), it is important to highlight its role and related mechanisms in psychological symptoms.

One of these related mechanisms is self-handicapping, because individuals with higher perfectionistic expectancies are more likely to use self-handicapping behaviors (Frost, Marten, Lahart, \& Rosenblate, 1990; Pulford, Johnson, \& Awaida, 2005). Self-handicapping is a cognitive strategy which people generally use for protecting their self-esteem by avoiding any effort, in the case of possible failure (Kolditz \& Arkin, 1982). Although these strategies seem to be useful in the short term; they might lead to negative psychological consequences in the long run (Zuckerman, Kieffer, \& Knee, 1998; Zuckerman \& Tsai, 2005).

In contrast to self-handicapping, self-compassion is a well-being enhancing attitude which enables people to handle with a negative situation or failure in an adaptive way (Akın \& Akın, 2015). People having higher level of self-compassion are more likely to attribute their personal experiences to their own abilities without comparing their achievements and abilities with others (Neff, 2011); to accept their failures (Neff, Rude \& Kirkpatrick, 2007) and to focus on gaining new experiences instead of trying to protect their self-esteem (Neff \& Vonk, 2009). Therefore, self-compassion might be functional coping mechanism, with respect to perfectionism and self-handicapping, in order to protect and flourish psychological health.

To sum up, providing a better understanding about the multidimensional nature of perfectionism by considering related risk and protective factors is important for achieving comprehensive theoretical and practical knowledge. Therefore, the aim of the current study was to examine the relationships among different perfectionism traits, self-handicapping, self-compassion and the predictive roles of these on psychological symptoms. 


\section{Method}

\subsection{Participants}

653 volunteer participants (360 females, 293 males) were recruited from various cities in Turkey by using convenient sampling method. The age range of the participants was between 18 and 50 $(M=24.90, S D=7.57)$. Majority of the participants $(89 \%)$ were either university students or had a minimum bachelor's degree. 488 of the participants (74.7\%) are married and 101 of them (15.6\%) were single.

\subsection{Measures}

Multidimensional Perfectionism Scale (Hewitt \& Flett, 1991b) was used in order to examine different perfectionism traits. The scale consists of 45 items with 3 subscales, namely: self-oriented perfectionism, others-oriented perfectionism and socially prescribed perfectionism. Turkish adaptation study of the Multidimensional Perfectionism Scale was conducted by Oral (1999). In the present study, Cronbach's alpha coefficient for internal consistency was found as .86 for total scale, .86 for self-oriented perfectionism, .67 for others-oriented perfectionism and .78 for socially prescribed perfectionism.

Self-handicapping Scale (Jones \& Rhodewalt, 1982) was used to assess self-handicapping strategies such as procrastination, lack of preparation and effort, use of alcohol and medicine, substance abuse, lack of sleep and emotional symptoms. Turkish version (Akın, 2012) was administered and its reliability was calculated as .71 in the current study.

The Self-Compassion Scale (Neff, 2003b) was used in order to measure individual's tendency to be compassionate toward self. The scale consists of 26 items with 6 subscales, namely: self-kindness vs self-judgment, common humanity vs isolation, mindfulness vs over identification. Turkish version (Akın, Akın, Abac1, 2007) was administered in this study and Cronbach's alpha coefficient was reported as .92 for total scale, .79 for self-kindness, .84 for self-judgment, .74 for common humanity, .76 for isolation, .77 for mindfulness, .78 for over-identification.

Brief Symptom Inventory (Derogatis, 1993) was administered to examine participants' psychological symptoms. The original form consists of 53 items with 9 subscales (somatization, obsessive-compulsive, interpersonal sensitivity, depression, anxiety, hostility, phobic anxiety, paranoid ideation, and psychoticism) and 3 indices of global stress (Global Severity Index, Positive Symptom Distress Index, and Positive Symptom Total). Turkish version of this scale (Şahin \& Durak, 1994) contains only 5 subscales; anxiety, depression, paranoid ideation and hostility. In the current study, reliability was reported as .97 for total scale, .89 for anxiety, .91 for depression, .90 for paranoid ideation, .85 for somatization and .82 for hostility.

\subsection{Procedure and analysis}

After the approval of Maltepe University Ethics Committee, self-report questionnaires were administered to volunteer participants by paper-pencil technique or via online survey. Participants signed an inform consent informing them about the purpose and the procedure of the study. It took approximately 20 minutes to complete all items. Collected data was analyzed by using SPSS IBM 23. Firstly, Cronbach's alpha coefficients were calculated for all the scales. Secondly, relationships among variables were examined with Pearson's Correlation Analysis. Thirdly, predictors of psychological symptoms were assessed with hierarchical regression analysis.

\section{Results}

\subsection{Intercorrelations among variables of the study}

Since the sample size is large, only correlation coefficients above .20 were accepted as significant. The findings revealed that total perfectionism was positively correlated with self-judgment $(r=.25, p<.001)$, isolation $(r=.32, p<.001)$ and over-identification $(r=.22, p<.001)$; but negatively correlated with total self-compassion $(r=-.28, p<.001)$. Additionally, socially prescribed perfectionism was positively correlated with self-handicapping $(r=.31, p<.001)$, self-judgment $(r=.35, p<.001)$, isolation $(r=.37, p<.001)$ and over-identification $(r=.30, p<.001)$, while negatively correlated with total self-compassion $(r=-.37, p<.001)$, self-kindness $(r=-.22, p<.001)$, common humanity $(r=-.20$, $p<.001)$ and mindfulness $(r=-.21, p<.001)$. Moreover, self-handicapping was positively correlated with self-judgment $(r=.54, p<.001)$, isolation $(r=.55, p<.001)$ and over-identification $(r=.61$, $p<.001)$; but negatively correlated with total self-compassion $(r=-.58, p<.001)$, self-kindness $(r=-.35$, $p<.001)$ and mindfulness $(r=-.39, p<.001)$ (See Table 1). 
Table 1. Intercorrelations among Variables of the Study.

\begin{tabular}{|c|c|c|c|c|c|c|c|c|c|c|}
\hline Variable & 1 & 2 & 3 & 4 & 5 & 6 & 7 & 8 & 9 & 10 \\
\hline 1 & 1 & $.67^{* *}$ & $-.28^{* *}$ & $-.15^{* *}$ & $.25^{* *}$ & $-.18^{* *}$ & $.32^{* *}$ & $-.12^{*}$ & $.22^{* *}$ & $.10^{*}$ \\
\hline 2 & & 1 & $-.37^{* *}$ & $-.22^{* *}$ & $.35^{* *}$ & $-.20^{* *}$ & $.37^{* *}$ & $-.21^{* *}$ & $.30^{* *}$ & $.31^{* *}$ \\
\hline 3 & & & 1 & $-.80^{* *}$ & $-.81^{* *}$ & $.56^{* *}$ & $-.75^{* *}$ & $.76^{* *}$ & $-.79^{* *}$ & $-.58^{* *}$ \\
\hline 4 & & & & 1 & $-.49^{* *}$ & $.58^{* *}$ & $-.37^{* *}$ & $.71^{* *}$ & $-.44^{* *}$ & $-.35^{* *}$ \\
\hline 5 & & & & & 1 & $-.21^{* *}$ & $.71^{* *}$ & $-.39^{* *}$ & $.71^{* *}$ & $.54^{* *}$ \\
\hline 6 & & & & & & 1 & $-.15^{* *}$ & $.55^{* *}$ & $-.16^{* *}$ & $-.11^{*}$ \\
\hline 7 & & & & & & & 1 & $-.36^{* *}$ & $.72^{* *}$ & $.55^{* *}$ \\
\hline 8 & & & & & & & & 1 & $-.48^{* *}$ & $-.39^{* *}$ \\
\hline 9 & & & & & & & & & 1 & $.61^{* *}$ \\
\hline 10 & & & & & & & & & & 1 \\
\hline \multicolumn{11}{|c|}{$\begin{array}{l}\text { Note: }{ }^{*} p<.01,{ }^{* *} p<.001 ; 1=\text { Multidimensional Perfectionism Scale total, } 2=\text { Multidimensional } \\
\text { Perfectionism Scale-Socially Prescribed Perfectionism, } 3=\text { Self-compassion Scale total, } 4=\text { Self-compassion } \\
\text { Scale-Self-kindness, } 5=\text { Self-compassion Scale-Self-judgment, } 6=\text { Self-compassion Scale-Common } \\
\text { humanity, } 7=\text { Self-compassion Scale-Isolation, } 8=\text { Self-compassion Scale-Mindfulness, } 9=\text { Self-compassion } \\
\text { Scale-Over-identification, } 10=\text { Self-handicapping Scale }\end{array}$} \\
\hline
\end{tabular}

\subsection{Predictors of psychological symptoms}

In order to examine the factors associated with psychological symptoms (as dependent variable), hierarchical regression analysis was performed. Independent variables entered into the equation via three steps via stepwise method. In the first step, age, education level and gender were entered to the regression analysis as control variables. In the second step, 3 perfectionism traits were entered. Finally, self-handicapping and self-compassion were entered in the third step.

The findings of the analysis indicated that age $[\beta=-.14, t(650)=-3.50, p<.001, p r=-.14]$ was entered into the equation as a controlled variable and explained $\% 2$ of the variance in psychological symptoms by itself, $F$ change $(1,650)=12.22, p<.001$. After controlling for demographic variables, only socially prescribed perfectionism $[\beta=.35, t(649)=9.72, p<.001, p r=.36]$ was significant predictor of psychological symptoms and increased the explained variance to $\% 14, F_{\text {change }}(1,649)=94.56, p<.001$. Thirdly, self-handicapping $[\beta=.48, t(648)=14.21, p<.001, p r=.49]$ was entered into the equation and increased the explained variance to $\% 34, F_{\text {change }}(1,648)=201.91, p<.001$. Lastly, self-compassion $[\beta=-.31, t(647)=-8.08, p<.001, p r=-.30]$ was also significant associated with symptoms and explained variance increased $\% 40, F_{\text {change }}(1,647)=65.25, p<.001$ (See Table 2). According to these results, after controlling demographic variables, increase in socially prescribed perfectionism and self-handicapping; and also decrease in self-compassion were significantly associated with increase in psychological symptoms.

Table 2. Predictors of Psychological Symptoms.

\begin{tabular}{|c|c|c|c|c|c|c|}
\hline & $F_{\text {change }}$ & $d f$ & $\boldsymbol{\beta}$ & $t$ & $p r$ & $\operatorname{Adj} . R^{2}$ \\
\hline \multicolumn{7}{|c|}{ Step 1: Demographic Variables } \\
\hline Age & 12.22 & 1,650 & -.14 & $-3.50^{*}$ & -.14 & .02 \\
\hline \multicolumn{7}{|c|}{ Step 2: Perfectionism } \\
\hline MPS-SPP & 94.56 & 1,649 & .35 & $9.72^{*}$ & .36 & .14 \\
\hline \multicolumn{7}{|c|}{$\begin{array}{l}\text { Step 3: Self-handicapping and } \\
\text { Self-compassion }\end{array}$} \\
\hline SHS & 201.91 & 1,648 & .48 & $14.21^{*}$ & .49 & .34 \\
\hline SCS total & 65.25 & 1,647 & -.31 & $-8.08^{*}$ & -.30 & .40 \\
\hline
\end{tabular}

\section{Discussion}

The current study aimed to examine the associations among different perfectionism traits, self-handicapping, self-compassion and psychological symptoms. Firstly, results showed that total perfectionism and socially prescribed perfectionism were negatively correlated with total self-compassion and its positive subscales, namely: self-kindness, common humanity and mindfulness; while positively 
correlated with negative subscales of self-compassion, namely, self-judgment, isolation and over-identification. In addition to that, self-handicapping was positively correlated with perfectionism, but negatively correlated with self-compassion. These findings are in the line with the previous studies (Akın \& Akın, 2015; Ferrari et al., 2018; Hiçdurmaz \& Aydın, 2017; Petersen, 2014). Self-compassion and perfectionism seem to activate opposite responses in the case of failure. In other words, perfectionistic attitudes are related to self-judgement and self-criticism in the failure, while self-compassion refers to being open and kind toward self and promotes to learn from negative experiences. Consistently, perfectionist individuals are more likely to engage in self-handicapping strategies to protect self-esteem. On the other hand, self-compassionate people do not need to externalize their failures; hence, they do not need to benefit from self-handicapping strategies (Neff \& Vonk, 2009).

As another important finding, increase in psychological symptoms was associated with increase in socially prescribed perfectionism and self-handicapping, while decrease in self-compassion. These findings are consistent with previous studies indicating that trying to meet others' or society's expectations and self-handicapping strategies may lead to some psychological problems such as depression and anxiety (Frost, Heimberg, Holt, Mattia, \& Neubauer, 1993; Zuckerman \& Tsai, 2005); while self-compassion is a projective factors for these problems (Neff, 2003b; Sun, Chan, \& Chan, 2016).

The findings of the current study indicate that socially prescribed perfectionism is related to more self-handicapping behaviors and less self-compassionate attitudes and all are associated with psychological symptoms. This comprehensive framework may contribute to literature by highlighting the dimensional differences of perfectionism and its related mechanisms to explain psychological outcomes. In addition to that, current findings point that therapeutic interventions focusing on perfectionism driven thoughts and behaviors (e.g. self-handicapping strategies such as procrastination and lack of effort) are beneficial, as well as, mindful self-compassion programs may improve psychological health and life quality.

Current study has some limitations as well. Firstly, the participants were mostly composed from females or young adults. Therefore, future studies with sample from different socio-demographic characteristics are recommended. Moreover, due to the cross-sectional nature of the study, it is not possible to infer causality or directions about these associations. Longitudinal studies may provide more insight about these relationships. Lastly, future studies including particular clinical groups are recommended to achieve knowledge for the role of different dimensions of perfectionism and related self-handicapping strategies in various psychological disorders.

\section{References}

Akın, A. (2012). Kendini sabotaj ölçeği: Geçerlik ve güvenirlik çalışması. Eğitim ve Bilim, 164, 176-187.

Akın, A. ve Akın, Ü. (2015). The predictive role of self-compassion on self-handicapping in Turkish university students. Ceskoslovenská psychologie, 59(1), 33-43.

Akın, Ü., Akın, A., \& Abacı, R. (2007). Öz-duyarlık Ölçeği: Geçerlik ve güvenirlik çalışması. Hacettepe Üniversitesi Eğitim Fakültesi Dergisi, 33, 1-10.

Derogatis, L. R. (1993) The Brief Symptom Inventory (BSI): Administration, Scoring and Procedures Manual. National Computer Systems, Minneapolis.

Egan, S. J., Wade, T. D., \& Shafran, R. (2011). Perfectionism as a transdiagnostic process: A clinical review. Clinical Psychology Review, 31, 203-212.

Ferrari, M., Yap, K., Scott, N., Einstein, D. A., \& Ciarrochi, J. (2018). Self-compassion moderates the perfectionism and depression link in both adolescence and adulthood. PLoS ONE, 13(2): e0192022.

Frost, R. O, Heimberg, R. G., Holt C. S., Mattia J. I., \& Neubauer, A. L. (1993). A comparison of two measures of perfectionism. Personality and Individual Differences, 14(1), 119-126.

Frost, R. O., Marten, P., Lahart, C., \& Rosenblate, R. (1990). The dimensions of perfectionism. Cognitive Therapy and Research, 14(5), 449-468.

Hewitt, P. L. \& Flett, G. L. (1991b). Perfectionism in the self and social contexts: Conceptualization, assessment, and association with psychopathology. Journal of Personality and Social Psychology, 60(3), 456-470.

Hiçdurmaz, D. \& Aydın, A. (2017). Hemşirelik Öğrencilerinin Öz-Duyarlık ve Çok Boyutlu Mükemmelliyetçilik Düzeyleri Arasındaki İlişkiler ve Etkileyen Faktörler. Psikiyatri Hemşireliği Dergisi, 8(2), 86-94.

Jones, E. E. \& Rhodewalt, F. (1982). The Self-Handicapping Scale. (Available from Frederick Rhodewalt, Department of Psychology, University of Utah, Salt Lake City, UT 84112). 
Kolditz, T. A. \& Arkin, R. M. (1982). An impression management interpretation of the self-handicapping strategy. Journal of Personality and Social Psychology, 43(3), 492-502.

Neff, K. D. \& Vonk, R. (2009). Self-compassion versus global self-esteem: Two different ways of relating to oneself. Journal of Personality, 77, 23-50.

Neff, K. D. (2003b). The development and validation of a scale to measure self-compassion. Self and Identity, 2, 223-250.

Neff, K. D. (2011). Self-compassion, self-esteem, and well-being. Social and Personality Compass, 5, $1-12$.

Neff, K. D., Rude, S. S., \& Kirkpatrick, K. (2007). An examination of self-compassion in relation to positive psychological functioning and personality traits. Journal of Research in Personality, 41, 908-916.

Oral, M. (1999). The Relationship Between Dimensions of Perfectionism, Stressful Life Events and Depressive Symptoms in University Students a Test of Diathesis-Stress Model of Depression. (Unpublished Master's Thesis). Orta Doğu Teknik Üniversitesi, Ankara.

Petersen, L. E. (2014). Self-compassion and self-protection strategies: The impact of self-compassion on the use of self-handicapping and sandbagging. Personality and Individual Differences, 56, 133-138.

Pulford, B. D., Johnson, A., \& Awaida, M. (2005). A cross-cultural study of predictors of self-handicapping in university students. Personality and Individual Differences, 39, 727-737.

Şahin, N. H. \& Durak, A. (1994). Kısa Semptom Envanteri: Türk gençleri için uyarlanması. Türk Psikoloji Dergisi, 9(31), 44-56.

Stoeber, J. \& Otto, K. (2006). Positive conceptions of perfectionism: Approaches, evidence, challenges. Personality and Social Psychology Review, 10, 295-319.

Stoeber, J., Schneider, N., Hussain, R., \& Matthews, K. (2014). Perfectionism and negative affect after repeated failure: Anxiety, depression, and anger. Journal of Individual Differences, 42(7), 1379-1389.

Sun, X., Chan, D. W., \& Chan, L. (2016). Self-compassion and psychological well-being among adolescents in Hong Kong: Exploring gender differences. Personality and Individual Differences, $101,288-292$.

Zuckerman, M. \& Tsai, F. (2005). Costs of self-handicapping. Journal of Personality, 73, 411-442.

Zuckerman, M., Kieffer, S. C., \& Knee, R. (1998). Consequences of self-handicapping: Effects on coping, academic performance, and adjustment. Journal of Personality and Social Psychology, 74, $1619-1628$ 